\title{
1 Analysis of red wines using an electronic tongue and infrared spectroscopy. Correlations with phenolic content and color parameters
}

C. Garcia-Hernandez ${ }^{\mathrm{a}, \mathrm{b}}$, C. Salvo-Comino ${ }^{\mathrm{a}, \mathrm{b}}$, F. Martin-Pedrosa ${ }^{\mathrm{a}, \mathrm{b}}$, C. Garcia-Cabezon ${ }^{\mathrm{a}, \mathrm{b}^{*}}$,

\section{*Corresponding authors:}

13 Prof. Maria Luz Rodriguez-Mendez, Dpt. Inorganic Chemistry, Engineers School,

14 Universidad de Valladolid, Paseo del Cauce, 59, 47011 Valladolid, Spain. Tel: +34-983

15 423540; e-mail: mluz@eii.uva.es

16 Prof. Cristina Garcia-Cabezon, Dpt. Materials Science, Engineers School, Universidad de

17 Valladolid, Paseo del Cauce, 59, 47011 Valladolid, Spain. Tel: +34-983 423540; e-mail: 


\section{Abstract}

21 The objective of this work was to develop a methodology based on multiparametric

22 methods (FTIR and a voltammetric e-tongue based on SPE) to evaluate simultaneously

23 fourteen parameters related to the phenolic content of red wines. Eight types of Spanish

24 red wines, elaborated with different grape varieties from different regions and with

25 different aging, were analyzed with both systems. Input variables used for multivariate analysis were extracted from FTIR spectra and voltammograms using the kernel method.

27 PCA analysis could discriminate wines according to their phenolic content with PC1,

28 PC2 and PC3 explaining the $99.8 \%$ of the total variance between the samples for FTIR

29 analysis and $85.8 \%$ for the e-tongue analysis. PLS calculations were used to establish

30 regression models with phenolic content parameters measured by UV-Vis spectroscopy

31 (TPI, Folin-Ciocalteu, CIELab and Glories) with high correlation coefficients $\left(\mathrm{R}^{2}>\right.$

32 0.85), and low RMSEs (<3.0) and number of factors $(<4)$. Both, PCA and PLS, were

33 carried out using the full cross validation method. As time is a critical factor in the food

34 industry, the main advantage of these multivariate techniques is their capability to

35 evaluate many parameters in a single experiment and in shorter time than using

36 independent classical techniques.

38 Keywords: Red wines; Electronic tongue; ATR-FTIR; Phenolic content. 
39 Abbreviations: e-tongue (electronic tongue); D.O. (Denomination of Origin); SPE 40 (Screen Printed Electrode); PCA (Principal Component Analysis); PLS (Partial Least 41 Squares); TPI (Total Polyphenol Index); PC (Principal Component).

\section{Introduction}

46 Phenolic compounds (phenolic acids, flavonoids and tannins) are important components

47 of wines as they can strongly influence their final organoleptic properties (Pinelo, 48 Arnous, \& Meyer, 2006; Setford, Jeffery, Grbin, \& Muhlack, 2017; Aleixandre-Tudo \&

49 Du Toit, 2018; Blanco-Vega, Gomez-Alonso, \& Hermosin-Gutierrez, 2014). In fact, the

50 characteristic color in red wines is to a large extent ascribable to the phenolic substances

51 present in the grape skin cells, which are transferred to the must during the maceration

52 step. However, wine color is also influenced by the oenological practices such as, storage

53 temperatures, length of storage and oxygen exposure (Atasanova, Fulcrand, Cheynier, \&

54 Moutounet, 2002; Obreque-Slier et al., 2013; Pinelo, Arnous, \& Meyer, 2006;

55 Ferreiro-Gonzalez et al., 2019). During conservation and aging of red wines, the

56 concentration of anthocyanins, the main responsible for wine color, decreases

57 progressively due to their reaction with other phenolic compounds, mainly with

58 flavanols. This phenomenon causes the color change from red-bluish of young wines towards reddish-brown of matured wines, as well as a decrease of wine astringency 
60 (Atasanova, Fulcrand, Cheynier, \& Moutounet, 2002). Color also gives information

61 about possible defects and changes during storage. Therefore, color is an important

62 parameter in the quality control of wines.

63 Traditionally, the color of wines has been measured using Glories parameters and

64 CIELab coordinates, a classical method established by the Commission Internationale of

65 L'Eclairage (CIE) (Esparza, Santamaria, Calvo, \& Fernandez, 2009; Rinaldi, Coppola, \&

66 Moio, 2019; Perez-Magariño \& Jose, 2002; Atasanova, Fulcrand, Cheynier, \&

67 Moutounet, 2002).

68 In addition, the phenolic and antioxidant content in wines samples can be assessed by

69 other recognized traditional spectrophotometric methods such as Total Polyphenol Index

70 (TPI), FRAP, DPPH, ORAC, and Folin-Ciocalteu Index, among others. These methods

71 are usually based on the evaluation of the capabilities of an oxidizing agent to induce an

72 oxidative damage to a substrate. However, up to now, a single method has not been

73 recognized as the most adequate, and the results obtained depend on the method used.

74 When approaching the study of the phenolic and antioxidant activity of wines, it has been

75 recommended to use more than one method (Barros, Andrade, Denadai, Nunes, \&

76 Narain, 2017; Lima et al., 2014).

77 The time is a critical factor in the food industry and for this reason the development of

78 new analytical tools to determine the phenolic content and the antioxidant capacity of

79 food is required. 
80 In recent years, multi-parametric methods have been applied in food industry (Smyth \&

81 Cozzolino, 2013). Infrared spectroscopy (FTIR, NIR) combined with chemometric

82 methods is emerging as a useful technique to analyze red wines. It is rapid, versatile and

83 require minimal sample preparation (Ferreiro-Gonzalez et al., 2019; Preserova, Ranc,

84 Milde, Kubistova, \& Stavek, 2015; Kadiroglu, 2018; Silva, Feliciano, Boas, \& Bronze,

85 2014). For instance, combining Near Infrared Spectra with statistical analysis, it is

86 possible to determine parameters such as the sugar content (Fernandez-Novales, Lopez,

87 Sanchez, Morales, \& Gonzalez-Caballero, 2009), acidity (Chauchard, Cogdill, Roussel,

88 Roger, \& Bellon-Maurel, 2004), pH value (Larrain, Guesalaga, \& Agosin, 2008) or

89 chloride and sulfate (Dos Santos, Pascoa, Porto, Cerdeira, \& Lopes, 2016) in red wines.

90 Similarly, through analysis with FTIR combined with chemometric techniques, sugar,

91 sulfur dioxide content or $\mathrm{pH}$ can be measured (Bauer et al., 2008).

92 Additionally, electronic tongues (e-tongues) based on electrochemical sensors

93 (potentiometric, amperometric, voltammetric or impedimetric) have been developed and

94 used in food quality control (Rodriguez-Mendez, 2016; Jiang, Zhang, Bhandari, \&

95 Adhikari, 2018; Sanaeifar, ZakiDizaji, Jafari, \& de la Guardia, 2017; Riul, Dantas,

96 Miyazaki, \& Oliveira, 2010; Peris \& Escuder-Gilabert, 2016; Ghasemi-Varnamkhasti,

97 Apetrei, Lozano, \& Anyogu, 2018). In this sense, electrochemical techniques can

98 represent an advantage thanks to higher sensitivity and relatively low cost in comparison

99 with the spectroscopic methods. 
100 E-tongues have been successfully applied to analyze wines (Apetrei et al., 2012;

101 Rodriguez-Mendez et al., 2014; Lvova et al., 2018; Merkyte, Morozova, Boselli, \&

102 Scampicchio, 2018; Rudnitskaya et al., 2017; Garcia-Hernandez, Comino,

103 Martin-Pedrosa, Rodriguez-Mendez, \& Garcia-Cabezon, 2018), beers (Gutierrez et al,

104 2013) and strong alcoholic beverages (spirits and liqueurs) (Novakowski, Bertotti, \&

105 Paixao, 2011) as well as to evaluate the quality of non-alcoholic beverages (Pascual et al.,

106 2018; Winquist, Olsson \& Eriksson, 2011; Ghasemi-Varnamkhasti et al., 2011).

107 The objective of this work is to evaluate and compare the capabilities of two multiparametric methods based on different working principles (electrochemical signals

109 and vibrational spectroscopy) to assess the phenolic content in red wines with different

110 characteristics (aging and grape variety). On one hand, a voltammetric e-tongue using

111 disposable and cheap sensors based on screen-printed technology has been implemented.

112 On the other hand, wines have been analyzed using FTIR spectroscopy, were the spectral

113 range corresponding to the fingerprint region $\left(1500-1000 \mathrm{~cm}^{-1}\right)$ has been selected for data

114 treatment. In both cases the input data for further statistical analysis have been extracted

115 using kernel functions. Chemometric tools such as Principal Component Analysis (PCA)

116 and Partial Least Squares (PLS-1) have been implemented to discriminate between wines

117 samples and to establish correlations with classical parameters related to phenolic content

118 of the antioxidant capacity such as CIELab coordinates, Glories parameters, TPI and

119 Folin-Ciocalteu index. The performance of both multiparametric systems has been 120 analyzed and compared. 
122 2. Materials and methods

\subsection{Reagents and solutions}

124 All chemicals and solvents were of reagent grade and used without further purification.

125 Sodium carbonate (anhydrous, powder, 99.99\%), Folin-Ciocalteu reagent, and ethanol

126 (absolute, $\geq 99.8 \%$, GC) were purchased from Sigma-Aldrich (St. Louis, MO, USA).

128 2.2. Wine samples

129 Spanish red wine samples elaborated with different grape varieties from different regions

130 (DO) (Tempranillo from Ribera de Duero origin; Tempranillo from Toro origin; Syrah

131 from Rioja origin; and a coupage of Tempranillo, Graciano and Mazuelo from Rioja

132 origin) and with different aging (Joven -young ine that has not been aged in oak barrel-;

133 Crianza -aged a minimum of 24 months and at least 6 of them in oak barrel-; Reserva

134 -minimum aging period of 36 months and at least 12 of them in oak barrel-; and Gran

135 Reserva -wines aged for 60 months and at least 18 of them in oak barrels-) were analyzed

136 (Table 1). Samples were provided by the Oenological Centers of Rueda (Valladolid,

137 Spain) and Haro (La Rioja, Spain). 
140 Polyphenol content was measured following official methods (OIV, 2013) using a

141 spectrophotometer Shimadzu UV-1603 (Kyoto, Japan) with a $10.0 \mathrm{~mm}$ path length quartz

142 cuvettes.

143 Determination of TPI280. Red wine was diluted with ultrapure water (1:100) and the

144 absorbance was measured directly at $280 \mathrm{~nm}$. The value of TPI 280 was calculated as the

145 absorbance x 100 .

146 Determination of Folin-Ciocalteu Index. Red wine samples were diluted 1:5 in

147 ultrapure water. Then, $0.1 \mathrm{ml}$ volume of red wine sample, $5 \mathrm{ml}$ of distilled water, $0.5 \mathrm{ml}$

148 of Folin-Ciocalteu reagent, and $2 \mathrm{ml}$ of $20 \% \mathrm{w} / \mathrm{w}$ sodium carbonate solution were

149 introduced in a $10 \mathrm{ml}$ calibrated flask, diluted to volume with distilled water and allowed

150 to stand for $30 \mathrm{~min}$ before measuring the absorbance at $750 \mathrm{~nm}$. The same procedure but

151 replacing the $0.1 \mathrm{ml}$ of wine sample with distilled water was used for determining the

152 blank value. The value of the total polyphenol index is given by the absorbance $\mathrm{x} 100$ for

153 red wines.

154 Glories parameters. Absorbance values at 420, 520 and $620 \mathrm{~nm}$ were measured to

155 determine Glories parameters (Perez-Magariño \& Jose, 2002): color density (CD), color

156 intensity $(\mathrm{CI})$, hue $(\mathrm{H})$, proportion of red color produced by flavylium cations $(\mathrm{dA} \%)$,

157 proportion of yellow color (Y\%), proportion of red color $(\mathrm{R} \%)$ and proportion of blue

158 color $(\mathrm{B} \%)$.

$159 C D=A 420+A 520$

$160 \quad C I=A 420+A 520+A 620$ 
$162 d A \%=(A 520-((A 420-A 620) / 2) / A 520) * 100$

$163 Y \%=A 420 / C I \times 100$

$164 R \%=A 520 / C I \times 100$

$165 B \%=A 620 / C I \times 100$

167 CIELab coordinates were determined by measuring the transmittance of the wine every

$16810 \mathrm{~nm}$ over the visible spectrum (from 380 to $780 \mathrm{~nm}$ ) using the illuminant D65 and $10^{\circ}$

169 standard observer, following the CIE recommendations (Commission Internationale of

170 L'Eclairage) (Sliwinska et al., 2016). These parameters are: $\mathrm{a}^{*}$ (redness or $-\mathrm{a}^{*}$ :

171 greenness), $b^{*}$ (yellowness or $-b^{*}$ : blueness), $L^{*}$ (lightness), $C^{*}$ (chroma or saturation)

172 and $\mathrm{h} *$ (hue angle).

173 2.4. Electronic tongue

174 A voltammetric electronic tongue based on screen-printed electrodes, SPEs (DropSens,

175 Asturias, Spain), has been used to analyze the wines by means of cyclic voltammetry. For

176 this purpose, six SPEs with different materials as working electrode were selected. Each

177 sensor device contained a reference electrode $(\mathrm{Ag})$, an auxiliary electrode $(\mathrm{C}$ or $\mathrm{Pt})$ and a

178 working electrode (Table 2). 
181 A Jasco Model FT/IR-6600 Spectrometer (Tokyo, Japan) with a diamond ATR crystal

182 accessory was used. The software used for FTIR data collection was Spectra Manager II

183 (Jasco, Tokyo, Japan). Before the analysis the instrument was purged with nitrogen for 10

184 min. As reference, the background spectrum of air (100 BKG) was collected before the

185 acquisition of the sample spectrum. After each sample, the crystal was rinsed with ethanol

186 with a cotton swab and dried. To record spectra, wine samples were dropped on the ATR

187 crystal. Spectra were recorded at $26{ }^{\circ} \mathrm{C}$ with a resolution of $2 \mathrm{~cm}^{-1}$ and 300 scans were

188 averaged for each spectrum (scan from 4000 to $400 \mathrm{~cm}^{-1}$ ).

189

190

191

2.6. Data preprocessing and chemometric analysis

192 The multivariate data analysis was performed by using Matlab v2014b (The Mathworks

193 Inc., Natick, MA, USA) and The Unscrambler (CAMO Software AS, Oslo, Norway).

194 Voltammograms and ATR-FTIR spectra provided curves with a high number of variables

195 that must be pre-treated to select a reduced number of variables without a loss of

196 information. Data pre-processing has been done based on a compression method

197 described by Gutierrez-Osuna \& Nagle (1999). Voltammogram curves were multiplied

198 by 10 smooth and bell-shaped windowing function (8) while infrared spectra were

199 multiplied by 30 smooth and bell-shaped windowing function (8) (Gutierrez-Osuna \&

200 Nagle, 1999, Medina-Plaza et al., 2016; Muñoz et al., 2018).

$201 \quad K$ 
where $a_{i}, b_{i}$ and $c_{i}$ define the width, shape and center of the different windowing functions

$203 \mathrm{~K}_{\mathrm{i}}, \mathrm{x}_{\mathrm{j}}$ is the $\mathrm{X}$-variable, for voltammetric data is the voltage while for infrared spectra is 204 the frequency in wavenumbers. The input voltammetric data matrix contained 205 information of " 8 wine samples with 5 replicas" $\times$ " 10 kernels per voltammogram" $\times$ " 6 206 sensors" extracted from the voltammogram signals acquired between -1.0 and $1.0 \mathrm{~V}$. 207 Additionally, ATR-FTIR data matrix includes information of " 8 wine samples with 3 208 replicas" × “30 kernels per spectrum" from the spectra region ranged from 1500-1000

$209 \mathrm{~cm}^{-1}$ where higher differences in the transmittance values were observed (RSD, relative

210 standard deviation, between transmittance values were higher). The number of variables 211 used for spectra data analysis (30 kernel functions) was higher than the number of 212 variables selected for the voltammetric signals (10 kernel functions) due to x-axis of IR 213 spectra contain more information than the $\mathrm{x}$-axis of voltammetric curves.

214 These sets of variables were then used as the input for different statistical analysis:

215 Principal Component Analysis (PCA) to discriminate wine samples, Partial Least 216 Squares regression (PLS-1) to study the correlation between the results obtained with the 217 electronic tongue and FTIR with the chemical parameters of phenolic content.

\section{3. Results and discussion}

221 Table 3 collects TPI280 and Folin-Ciocalteu Indexes measured in wines. As expected, 222 whatever the variety of grape, young wines showed higher absorbance values than aged 
wines, confirming that the phenolic content decreased due to the polymerization of

224 phenolic compounds that occurs during aging. This polymerization produces a decrease in the concentration of low molecular weight polyphenolic compounds and increases the concentration of polymeric polyphenols, affecting the wine color (Atasanova, Fulcrand, Cheynier, \& Moutounet, 2002). The TPI and Folin-Ciocalteu indexes of wines with similar aging also vary from one variety to another.

\section{<Table 3>}

230 Glories parameters were used to evaluate the portion of red, yellow and blue color in

231 wines (Table 4). Due to the polymerization reactions and co-pigmentation of 232 anthocyanins occurring during the aging, wines change their color from intense red to 233 brown red. In good accordance with this idea, Glories parameters showed that red portion 234 (R\%) was higher in Joven wines as well as the color intensity values did. On the other 235 hand, yellow portion (Y\%), which contributes to brown color appearance, and 236 hue/tonality $(\mathrm{H})$, increased during aging reaching higher values in older wines. As 237 expected, Blue portion (B\%), the main responsible for red-bluish color, showed higher 238 values in young wines. However, this difference was not so clear in wines of the D.O. 239 Toro, which presented similar values of $\mathrm{B} \%$. Again, $\mathrm{R} \%, \mathrm{Y} \%$ and $\mathrm{B} \%$ were different is 240 wines elaborated from different grapes in spite of having the same time-aging.

242 Results obtained for CIELab color parameters (Table 5) were consistent with those 243 obtained with Glories parameters. As a general trend, a* (the parameter, responsible for 
244 red color) decreased during the aging while the parameter $b^{*}$ responsible for yellow

245 color, hue angle responsible for tonality $\left(\mathrm{h}^{*}\right)$ and lightness $\left(\mathrm{L}^{*}\right)$ increased. Again,

246 Reserva wines form Rioja prepared with the variety Syrah and the Coupage, showed

247 values relatively different to the wines prepared with the Tempranillo variety in spite of

248 having the same time-aging.

<Table 5>

250 3.2. E- tongue: Discrimination capability

251 The array of electrochemical sensors was immersed in the red wines. In all cases,

252 voltammograms showed a variety of peaks produced by components with redox activity

253 (i.e. polyphenols in the $0.4-0.8 \mathrm{~V}$ regions) and by the electrode modifiers.

254 In general, it was observed that in aged wines, the anodic peak at $+0.8 \mathrm{~V}$ showed higher

255 intensities than in voltammograms registered in younger wines (Figure 1). The increase is

256 due to the redox reactions of polyphenolic compounds formed during aging. Thus, this

257 increase is well correlated to the decrease of the phenolic content observed in TPI and

258 Folin-Cioacalteu, (as well as in the "red parameters" of Glories and CIELab analysis) that

259 occurs during the aging process in oak barrels where micro-oxygenation reduces the total

260 content of low molecular weight phenolic compounds as a result of condensation

261 reactions and increases the polymeric polyphenols which stabilize wine color (Behrends

$262 \&$ Weber, 2017). This effect has already been observed in e-tongues used to analyze

263 grape skins (Muñoz et al., 2018). 
265 Each sensor showed different features depending on the modifier: carbonaceous 266 electrodes (modified with carbon, CNT and MWCNT) showed anodic peaks at +0.5 and $267+0.8 \mathrm{~V}$ due to the oxidation of polyphenolic compounds of wines as well as a broad 268 reduction peak at around 0.0 V. Sensor modified with PANI showed broad peaks, NiO 269 showed the most intense responses while platinum could detect phenols and the 270 decomposition of water followed by the oxidation of hydrogen at negative potentials (ca. $271-0.45 \mathrm{~V})$.

272 The repeatability of the measurements was tested by calculating the coefficients of 273 variation in the intensity for 10 consecutive cycles. The coefficients of variation were 274 lower than $10 \%$.

275 The differences observed from one wine to another are due to their different phenolic 276 composition. That is, as each wine has a different phenolic composition, the oxidation 277 and reduction peaks appear at different potentials and show different intensities. The 278 precedent results demonstrated that the sensors included in the array produced a unique 279 response for each wine. In consequence, the response of the array can be considered a 280 fingerprint of each sample and can be used to discriminate wines.

281 Figure 2 shows the $2 \mathrm{D}$ scores plot obtained using the variables obtained using the kernel 282 method. PC1 and PC2 explained the $56.9 \%$ and $20.9 \%$ of the covariance respectively $283(\mathrm{PC} 1+\mathrm{PC} 2+\mathrm{PC} 3=85.8 \%)$. The diagram shows that all wines analyzed could be clearly 284 discriminated. In addition, wines with higher polyphenol index (Young and Crianza) 285 were located in the upper part of the diagram, in the region of positive PC2, confirming 
that the polyphenolic level plays an important role in the discrimination capabilities of the

287 electronic tongue.

288 With the purpose of identifying outliers in the sampling, Hotelling T2 was performed at $\alpha=0.05$ and after three PCA components. Hotelling T2-values for each sample were plotted under the critical test value and, therefore, no outliers were tagged.

\section{$<$ Figure 2>}

\subsection{ATR-FTIR: Discrimination capability}

294 ATR-FTIR average spectra of red wines are presented in Figure 3. All wine samples gave

295 rise to similar spectra patterns. The intense band detected in the $3700-2971 \mathrm{~cm}^{-1}$ region

296 originated from compounds with - $\mathrm{OH}$ groups such as water and ethanol, which are major

297 compounds in wine samples, was not useful in this work. The region $1500-1000 \mathrm{~cm}^{-1}$,

298 usually referred to as the "fingerprint" region, was selected for working range since the

299 RSD (relative standard deviation) between absorption values for the samples were high in

300 this region. Signals from phenols can be found in this region: the antisymmetric in-plane

301 bending of $-\mathrm{CH}_{3}$ at $1448-1444 \mathrm{~cm}^{-1}$, the symmetric in-plane bending of $-\mathrm{CH}_{3}$ at 302 1376-1373 $\mathrm{cm}^{-1}$, the absorption at $1340-1339 \mathrm{~cm}^{-1}$ assigned to $\mathrm{CH}$ bending and $\mathrm{CH}_{2}$ 303 wagging, the peak at $1281-1278 \mathrm{~cm}^{-1}$ corresponding to in-plane bending of $\mathrm{O}-\mathrm{H}$, and the 304 bands at $1207 \mathrm{~cm}^{-1}, 1110-1107 \mathrm{~cm}^{-1}, 1068-1062 \mathrm{~cm}^{-1}$ originated from the stretching 305 vibration of $\mathrm{C}-\mathrm{O}$. The $1382 \mathrm{~cm}^{-1}$ absorption band attributes to the $\mathrm{O}-\mathrm{H}$ in plane 306 deformation in polyphenols. The deformation vibration of the $\mathrm{C}-\mathrm{C}$ bonds in the phenolic 
307 groups adsorb in the region of $1500-1400 \mathrm{~cm}^{-1}$. These assignments are based on previous

308 work on phenolic compounds in wines (Silva, Feliciano, Boas, \& Bronze, 2014;

309 Cozzolino, Cynkar, Shah, \& Smith, 2011). ATR-FTIR spectra showed that the intensity

310 of these peaks in young wines (Joven Ribera and Joven Toro) was clearly higher than

311 long time-aged wines (Crianza, Reserva and Gran Reserva) because the polyphenolic

312 content in young wines is higher. Moreover, for the same D.O. Ribera wines absorbance

313 follows the sequence Joven, Crianza and Gran Reserva.

314 The repeatability of the measurements was tested by calculating the coefficients of

315 variation in the transmittance for 5 FTIR spectra. The coefficients of variation were lower

316 than $4 \%$.

317

<Figure 3>

318 PCA scores plot for FTIR data is shown in Figure 4. In this case, the first PC, explained

$31998.8 \%$ of the variance $(\mathrm{PC} 1+\mathrm{PC} 2+\mathrm{PC} 3=99.8 \%)$. FTIR signals were also able to

320 discriminate the wines analyzed. However, even if Young and Crianza wines were

321 mainly located on the left part of the diagram, this trend was not followed by the Crianza

322 Toro sample that appeared on the right part of the figure. This means that ATR-FTIR is

323 not so efficient to discriminate wines according to the polyphenolic content.

324 As in the case of e-tongue, Hotelling T2 was performed at $\alpha=0.05$ and after three PCA

325 components. Also in this case the Hotelling T2-values for each sample were plotted under

326 the critical test value. 
331 Regression models were built to correlate the e-tongue or the ATR-FTIR results with

332 TPI280, Folin-Ciocalteu, Glories or CIElab parameters using PLS-1. The validation 333 method used for PLS analysis was full cross validation ( $\mathrm{n}=40$ samples). Calibration fits

334 the model to the available data, while validation checks the model for new data. Results

335 of PLS-1 models are shown in Table 6. Both techniques showed good correlations with

336 the 14 parameters analyzed. Particularly good correlations were found with the TPI280

337 with the lowest number of latent variables ( 2 for e-tongue and 3 for ATR-FTIR). This is

338 illustrated in Figure 5 where the explained variance vs. the number of factors for the

339 PLS-1 models are represented. The models performed for each technique were

340 representative due to residual variance curves (calibration and validation) for each

341 technique are close together. As observed in the Figure the model correlating e-tongue

342 and TPI280 requires 2 factors (or latent variables) to explain $90 \%$ of the variance. The

343 similarity between calibration and validation curves corroborated the high quality of the

344 model. On the other hand, the PLS-1 model correlating the FTIR and the TPI280 requires

3453 latent variables to explain the $90 \%$ of the variance.

346 In conclusion, according to PLS analysis results, it can be concluded that e-tongue

347 analysis has a certain advantage over FTIR because it shows better correlations (higher 
348 coefficients of correlations and lower residual errors) with a lower number of latent

349 variables (factors).

350

<Table 6>

351

$<$ Figure 5>

352 An interesting advantage of the proposed multivariate techniques is that they reduce the time required to obtain information about 14 parameters.

354 The time required to analyze a wine sample with the e-tongue was about 6.5 minutes

355 (including 10 cycles to obtain a reliable response) and 10 minutes in the case of the FTIR

356 (300 scans). When systems are trained appropriately, the statistical data treatment takes

357 only few seconds.

358 In contrast, the assessment of the fourteen parameters studied here, requires four different

359 sets of experiments (TPI, Folin-Ciocalteu, CIELab and Glories parameters). The time

360 required in each technique is different, but time ranges from 5 to 20 minutes (for instance,

361 Folin requires 30 minutes before measuring the absorbance at $750 \mathrm{~nm}$ ). Other techniques

362 such as HPLC require larger times (typically 80 minutes/sample). Therefore, one can

363 conclude that the use of multivariate techniques like e-tongue and FTIR means a clear

364 advantage for reducing the time of the analysis.

366 4. Conclusions

367 Two multiparametric techniques, e-tongue and ATR-FTIR combined with an appropriate pre-processing method could be successfully used to discriminate red wines according to 

parameters related to the polyphenolic content and can be used to predict simultaneously TPI, Folin-Ciocalteu, CIELab and Glories parameters in a single experiment. This is an important advantage for the wine industry where time is a critical factor. E-tongue showed better correlations (higher coefficients of correlations and lower residual errors) with a lower number of latent variables (factors) than ATR-FTIR. In summary, these systems provide information about the phenolic content in a fast and reliable manner assessing more than one parameter at once.

\section{Acknowledgments}

380 The authors are grateful to the Oenological Centers of Rueda (Valladolid, Spain) and

381 Haro (La Rioja, Spain). Financial support by Ministry of Education and Science (Plan

382 Nacional: RTI2018-097990-B-I00) and the Junta de Castilla y Leon (VA275P18) is

383 gratefully acknowledged. Garcia-Hernandez thanks Junta de Castilla y León for a grant 384 (BOCYL-D-24112015-9).

\section{Conflicts of Interest}

386 The authors declare that they have no conflict of interest.

\section{References}


388 Aleixandre-Tudo, J.L. \& Du Toit, W. (2018). Cold maceration application in red wine production and its effects on phenolic compounds: A review. LWT-Food Science and Technology, 95, 200-208.

Apetrei, I.M., Rodriguez-Mendez, M.L., Apetrei, C., Nevares, I., del Alamo, M., \& de Saja, J.A. (2012). Monitoring of evolution during red wine aging in oak barrels and alternative method by means of an electronic panel test. Food Research International, 45, 244-249.

Atasanova, V., Fulcrand, H., Cheynier, W., \& Moutounet. M. (2002). Effect of Analytica Chimica Acta, 458, 15-27.

Barros, R.G.C., Andrade, J.K.S., Denadai, M., Nunes, M.L., \& Narain, N. (2017). Evaluation of bioactive compounds potential and antioxidant activity in some Brazilian exotic fruit residues. Food Research International, 102, 84-92.

Bauer, R., Nieuwoudt, H., Bauer, F.F., Kossmann, J., Koch, K.R., \& Esbensen, K.H. (2008). FTIR spectroscopy for grape and wine analysis. Analytical Chemistry, 80, 1371-1379.

Blanco-Vega, D., Gomez-Alonso, S., \& Hermosin-Gutierrez, I. (2014). Identification, 407 content and distribution of anthocyanins and low molecular weight anthocyanin-derived pigments in Spanish commercial red wines. Food Chemistry, $158,449-458$. 
408 Behrends A. \& Weber, F. (2017). Influence of Different Fermentation Strategies on the 409 Phenolic Profile of Bilberry Wine (Vaccinium myrtillus L.). Journal of $410 \quad$ Agricultural and Food Chemistry, 65, 7483-7490.

411 Chauchard, F., Cogdill, R., Roussel, S., Roger, J.M., \& Bellon-Maurel, V. (2004). spectroscopy:development of a robust and portable sensor for acidity prediction in grapes. Chemometrics and Intelligent Laboratory System, 71, 141-150.

415 Chung, N., Jo, Y., Joe, M.H., Jeong M.H., Jeong, Y.J., \& Kwon, J.H. (2017). Rice 416 vinegars of different origins: discriminative characteristics based on solid-phase $123,159-166$.

420 Cozzolino, D., Cynkar, W., Shah, N., \& Smith, P. (2011). Feasibility study on the use of attenuated total reflectance mid-infrared for analysis of compositional parameters

423 Dos Santos, C.A.T., Pascoa, R.N.M.J., Porto, P.A.L.S., Cerdeira, A.L., \& Lopes J.A. (2016). Application of Fourier-transform infrared spectroscopy for the determination of chloride and sulfate in wines. LWT-Food Science and Technology, 67, 181-186. 
427 Esparza, I., Santamaria, C., Calvo, I., \& Fernandez, J.M. (2009). Significance of 428 CIELAB parameters in the routine analysis of red wines. CYTA-Journal of Food, $429 \quad 7,189-199$.

430 Fernandez-Novales, J., Lopez, M.I., Sanchez, M.T., Morales, J., \& Gonzalez Caballero, V. (2009). Shortwave-near infrared spectroscopy for determination of reducing sugar content during grape ripening, winemaking and aging of White and red wines. Food Research International, 42, 285-291.

434 Ferreiro-Gonzalez, M., Ruiz-Rodriguez, A., Barbero, G.F., Ayuso, J., Alvarez, J.A., wines. Food Chemistry, 277, 6-11

438 Garcia-Hernandez, C., Comino, C.S., Martin-Pedrosa, F., Rodriguez-Mendez, M.L., \& Palma, M., \& Barroso, C.G. (2019). FT-IR, Vis spectroscopy, color and multivariate analysis for the control of ageing processes in distinctive Spanish

442 Ghasemi-Varnamkhasti, M., Apetrei, C., Lozano, J., \& Anyogu A. (2018). Potential use of electronic noses, electronic tongues and biosensors as multisensor systems for spoilage examination in foods. Trends in Food Science and Technology, 80, 71-92.

445 Ghasemi-Varnamkhasti, M., Mohtasebi, S.S., Rodriguez-Mendez, M.L., Siadat, M., 446 Ahmadi, H., \& Razavi, S.H. (2011). Electronic and bioelectronic tongues, two 

in Food Science and Technology 22, 245-248.

449 Gutierrez, J.M., Haddi, Z., Amari, A., Bouchikhi, B., Mimendia, A., Ceto, X., \& del discrimination of beers. Sensors and Actuators B, 177, 989-996.

452 Valle, M. (2013). Hybrid electronic tongue based on multisensor data fusion for

Gutierrez-Osuna, R. \& Nagle, H.T. (1999). A method for evaluating data-preprocessing techniques for odor classification with an array of gas sensors. IEEE Transactions on Systems Man and Cybernetics Part B, 29, 626-632.

Jiang, H.Y., Zhang, M., Bhandari, B., \& Adhikari, B. (2018). Application of electronic tongue for fresh foods quality evaluation: A review. Food Reviews International, 34, 746-769.

Kadiroglu, P. (2018). FTIR spectroscopy for prediction of quality parameters and antimicrobial activity of commercial vinegars with chemometrics. Journal of the Science of Food and Agriculture, 98, 4121-4127.

Larrain, M., Guesalaga, A.R., \& Agosin, E. (2008). A multipurpose portable instrument for determining ripeness in wine grapes using NIR spectroscopy. IEEE Transactions on Instrumentation and Measurement, 57, 294-302.

Lima, M.D., Silani, I.D.V., Toaldo, I.M., Correa, L.C., Biasoto, A.C.T., Pereira, G.E., Bordignon-Luiz M.T., \& Ninow, J.L. (2014). Phenolic compounds, organic acids and antioxidant activity of grape juices produced from new Brazilian varieties planted in the Northeast Region of Brazil. Food Chemistry, 161, 94-103. 
Lvova, L., Yaroshenko, I., Kirsanov, D., Di Natale, C., Paolesse, R., \& Legin, A. (2018). Electronic tongue for brand uniformity control: A case study of Apulian red wines recognition and defects evaluation. Sensors, 18, 1-12.

Magdas, D.A., Pinzaru, S.C., Guyon, F., Feher, I., \& Cozar, B.I.(2018). Application of SERS technique in white wines discrimination. Food Control, 92, 30-36.

Medina-Plaza, C., Garcia-Hernandez, C., de Saja, J.A., Fernandez-Escudero, J.A., Barajas, E., Medrano, G., Garcia-Cabezon, C., \& Rodriguez-Mendez, M.L. (2015). The advantages of disposable screen-printed biosensors in a bioelectronic tongue for the analysis of grapes. LWT-Food Science and Technology, 62, 940-947.

Merkyte, V., Morozova, K., Boselli, E., \& Scampicchio, M. (2018). Fast and simultaneous determination of antioxidant activity, total phenols and bitterness of red wines by a multichannel amperometric electronic tongue. Electroanalysis, 30, 314-319.

Muñoz, R., Garcia-Hernandez, C., Medina-Plaza, C., Garcia-Cabezon, C., Fernandez-Escudero, J.A., Barajas, E., Medrano, G., \& Rodriguez-Mendez, M.L. (2018). A different approach for the analysis of grapes: Using the skin as sensing element. Food Research International, 107, 544-550.

Novakowski, W., Bertotti, M., \& Paixao, T.R.L.C. (2011). Use of copper and gold electrodes as sensitive elements for fabrication of an electronic tongue: Discrimination of wines and whiskies. Microchemical Journal, 99, 145-151. 
OIV. The International Organisation of Vine and Wine (2013). Compendium of international methods of analysis of wines and musts (2 vol.).

490 Obreque-Slier, E., Peña-Neira, A., Lopez-Solis, R., Caceres-Mella, A., Toledo-Araya, H., \& Lopez-Rivera, A. (2013). Phenolic composition of skins from four Carmenet grape varieties (Vitis vinifera L.) during ripening. LWT-Food Science and Technology, 54, 404-413.

494

495

496

497

498

499

500

501

502

503

504

505

506

507

508

Pascual L., Gras M., Vidal-Brotons D., Alcaniz M., Martinez-Manez R., \& Ros-Lis J.V. (2018). A voltammetric e-tongue tool for the emulation of the sensorial analysis and the discrimination of vegetal milks. Sensors and Actuators B, 270, 231-238.

Perez-Magariño, S. \& Jose, I.L.G.S. (2002). Prediction of red and rose wine CIELab parameters from simple absorbance measurements. Journal of the Science of Food and Agriculture, 82, 1319-1324.

Peris, M. \& Escuder-Gilabert, L. (2016). Electronic noses and tongues to assess food authenticity and adulteration. Trends in Food Science and Technology, 58, 40-54.

Pinelo, M., Arnous, A., \& Meyer, A.S. (2006). Upgrading of grape skins: Significance of plant cell-wall structural components and extraction techniques for phenol release. Trends in Food Science and Technology, 17, 579-590.

Preserova, J., Ranc, V., Milde, D., Kubistova, V., \& Stavek J. (2015). Study of phenolic profile and antioxidant activity in selected Moravian wines during winemaking process by FT-IR spectroscopy. Journal of Food Science and Technology, 52, 6405-6414. 
Rinaldi, A., Coppola, M., \& Moio, L. (2019). Aging of Aglianico and Sangiovese wine on mannoproteins: Effect on astringency and colour. LWT-Food Science and Technology, 105, 233-241.

512 Riul, A., Dantas, C.A.R., Miyazaki, C.M., \& Oliveira, O.N. (2010). Recent advances in electronic tongues. Analyst, 135, 2481-2495.

514 Rodriguez-Mendez, M.L. (2016). Electronic noses and tongues in the food industry. Amsterdam, The Netherlands: Elsevier Academic Press.

516 Rodriguez-Mendez, M.L., Apetrei, C., Gay, M., Medina-Plaza, C., de Saja, J.A., Vidal, S., Aagaard, O., Ugliano, M., Wirth, J., \& Cheynier, V. (2014). Evaluation of oxygen exposure levels and polyphenolic content of red wines using an electronic panel formed by an electronic nose and an electronic tongue. Food Chemistry, 155, 91-97.

Rudnitskaya, A., Schmidtke, L.M., Reis, A., Domingues, M.R.M., Delgadillo, I., Debus, maceration with oak chips using an electronic tongue. Food Chemistry, 229, 20-27.

523 Sanaeifar, A., ZakiDizaji, H., Jafari, A., \& de la Guardia, M. (2017). Early detection of Analytical Chemistry, 97, 257-271.

526 Setford, P.C., Jeffery, D.W., Grbin, P.R., \& Muhlack, R.A. (2017). Factors affecting extraction and evolution of phenolic compounds during red wine maceration and the role of process modelling. Trends in Food Science and Technology, 69, 106-117. 
529

530

531

532

533

534

535

536

537

538

539

540

541

542 Zabadaj, M., Ufnalska, I., Chreptowicz, K., Mierzejewska, J., Wroblewski, W., \&

Silva, S.D., Feliciano, R.P., Boas, L.V., \& Bronze, M.R. (2014). Application of FTIR-ATR to Moscatel dessert wines for prediction of total phenolic and flavonoid contents and antioxidant capacity. Food Chemistry, 150, 489-493.

Sliwinska, M., Garcia-Hernandez, C., Koscinski, M., Dymerski, T., Wardencki, W., Namiesnik, J., Sliwinska-Bartkowiak, M., Jurga, S., Garcia-Cabezon, C., \& Rodriguez-Mendez, M.L. (2016). Discrimination of apple liqueurs (Nalewka) using a voltammetric electronic tongue, UV-Vis and Raman spectroscopy. Sensors, 16, 1-14.

Smyth, H. \& Cozzolino, D. (2013). Instrumental methods (spectroscopy, electronic nose, and tongue) as tools to predict taste and aroma in beverages: Advantages and limitations. Chemical Reviews, 113, 1429-1440.

Winquist, F., Olsson, J., \& Eriksson, M. (2011). Multicomponent analysis of drinking water by a voltammetric electronic tongue. Analytica Chimica Acta, 683, 192-197. Ciosek-Skibinska, P. (2017). Performance of hybrid electronic tongue and HPLC coupled with chemometric analysis for the monitoring of yeast biotransformation. Chemometrics and Intelligent Laboratory Systems, 167, 69-77. 


\section{$1 \quad$ List of Tables}

2

Table 1. Spanish red wines under study

\begin{tabular}{llc}
\hline \multicolumn{1}{c}{ Ageing } & D.O. & $\begin{array}{c}\text { Vitis vinifera } \boldsymbol{L} . \\
\text { Grape Variety }\end{array}$ \\
\hline Joven & Ribera & Tempranillo (Tinta del País) \\
Crianza & Ribera & Tempranillo (Tinta del País) \\
Gran Reserva & Ribera & Tempranillo (Tinta del País) \\
\hline Joven & Toro & Tempranillo (Tinta de Toro) \\
Crianza & Toro & Tempranillo (Tinta de Toro) \\
Reserva & Toro & Tempranillo (Tinta de Toro) \\
\hline Reserva & Rioja & Syrah \\
Reserva & Rioja & Tempranillo, Graciano, Mazuelo \\
& & (denoted as “coupage") \\
\hline
\end{tabular}

3 
Table 2. List of the SPE sensors forming the array

\begin{tabular}{ll}
\hline DropSens Ref. & SPE working electrode \\
\hline DRP-110 & Carbon \\
DRP-110NI & Nickel (II) Oxide / Carbon \\
DRP-110PANI & Polyaniline / Carbon \\
DRP-110CNT & Carboxyl functionalized Multi-Walled Carbon Nanotubes / Carbon \\
DRP-110SWCNT & Carboxyl functionalized Single-Walled Carbon Nanotubes / Carbon \\
DRP-550 & Platinum \\
\hline
\end{tabular}

5 
Table 3. TPI 280 and Folin-Ciocalteu Indexes measured in wines.

\begin{tabular}{lcccc}
\hline Red wine & $\begin{array}{c}\text { Absorbance } \\
\mathbf{( 2 8 0} \mathbf{~ n m})\end{array}$ & TPI280 & $\begin{array}{c}\text { Absorbance } \\
\mathbf{( 7 5 0 ~} \mathbf{~ m})\end{array}$ & $\begin{array}{c}\text { Folin-Ciocalteu } \\
\text { Index }\end{array}$ \\
\hline Joven (D.O. Ribera) & $0.67 \pm 0.05$ & $67 \pm 5$ & $0.73 \pm 0.08$ & $73 \pm 8$ \\
Crianza (D.O. Ribera) & $0.64 \pm 0.08$ & $64 \pm 8$ & $0.69 \pm 0.04$ & $69 \pm 4$ \\
Gran Reserva (D.O. Ribera) & $0.56 \pm 0.06$ & $56 \pm 6$ & $0.61 \pm 0.05$ & $61 \pm 5$ \\
\hline Joven (D.O. Toro) & $0.82 \pm 0.02$ & $82 \pm 2$ & $0.81 \pm 0.07$ & $81 \pm 7$ \\
Crianza (D.O. Toro) & $0.64 \pm 0.07$ & $64 \pm 7$ & $0.70 \pm 0.09$ & $70 \pm 9$ \\
Reserva (D.O. Toro) & $0.58 \pm 0.03$ & $58 \pm 3$ & $0.65 \pm 0.03$ & $65 \pm 3$ \\
\hline Reserva (D.O. Rioja) "Syrah" & $0.57 \pm 0.04$ & $57 \pm 4$ & $0.57 \pm 0.06$ & $57 \pm 6$ \\
Reserva (D.O. Rioja) "Coupage" & $0.59 \pm 0.04$ & $59 \pm 4$ & $0.64 \pm 0.08$ & $64 \pm 8$ \\
\hline
\end{tabular}

7 Data: mean $\pm \mathrm{SD}(\mathrm{n}=3)$.

8 
Table 4. Glories color parameters of red wines under study.

\begin{tabular}{|c|c|c|c|c|c|c|c|}
\hline Red wine & CD & CI & $\mathbf{H}$ & dA\% & Y\% & $\mathbf{R} \%$ & В\% \\
\hline Joven (D.O. Ribera) & $1.26 \pm 0.35$ & $1.47 \pm 0.25$ & $0.64 \pm 0.09$ & $81.56 \pm 2.19$ & $33.42 \pm 3.07$ & $52.52 \pm 3.85$ & $14.05 \pm 1.81$ \\
\hline Crianza (D.O. Ribera) & $1.09 \pm 0.17$ & $1.27 \pm 0.19$ & $0.78 \pm 0.06$ & $75.08 \pm 3.15$ & $37.88 \pm 3.21$ & $48.30 \pm 3.12$ & $13.81 \pm 1.53$ \\
\hline Gran Reserva (D.O. Ribera) & $0.94 \pm 0.23$ & $1.08 \pm 0.17$ & $0.81 \pm 0.07$ & $72.17 \pm 3.33$ & $39.26 \pm 2.37$ & $48.47 \pm 2.89$ & $12.28 \pm 1.52$ \\
\hline Joven (D.O. Toro) & $1.64 \pm 0.31$ & $1.87 \pm 0.23$ & $0.54 \pm 0.05$ & $83.65 \pm 4.52$ & $30.89 \pm 2.72$ & $56.80 \pm 2.78$ & $12.31 \pm 1.79$ \\
\hline Crianza (D.O. Toro) & $1.03 \pm 0.12$ & $1.17 \pm 0.14$ & $0.76 \pm 0.05$ & $74.36 \pm 3.62$ & $37.84 \pm 3.91$ & $49.91 \pm 3.78$ & $12.24 \pm 1.67$ \\
\hline Reserva (D.O. Toro) & $0.99 \pm 0.19$ & $1.13 \pm 0.21$ & $0.89 \pm 0.07$ & $68.80 \pm 2.70$ & $41.26 \pm 2.37$ & $46.50 \pm 2.56$ & $12.24 \pm 1.89$ \\
\hline Reserva (D.O. Rioja) "Syrah" & $1.29 \pm 0.15$ & $1.49 \pm 0.24$ & $0.76 \pm 0.08$ & $75.61 \pm 3.26$ & $37.36 \pm 3.62$ & $49.36 \pm 3.56$ & $13.28 \pm 2.31$ \\
\hline $\begin{array}{l}\text { Reserva (D.O. Rioja) } \\
\text { "Coupage" }\end{array}$ & $0.94 \pm 0.10$ & $1.07 \pm 0.21$ & $0.87 \pm 0.09$ & $69.48 \pm 2.57$ & $40.82 \pm 2.8$ & $47.10 \pm 3.41$ & $12.08 \pm 1.57$ \\
\hline
\end{tabular}

10 Data: mean $\pm \mathrm{SD}(\mathrm{n}=3)$.

$11 \mathrm{CD}$, color density; $\mathrm{CI}$, color intensity; $\mathrm{H}$, hue/tonality; $\mathrm{dA} \%$, proportion of red color produced by

12 flavylium cations; Y\%, proportion of yellow color; $\mathrm{R} \%$, proportion of red color; $\mathrm{B} \%$, portion of blue

13 color.

14 
Table 5. CIELab color coordinates of the red wines under study.

\begin{tabular}{lccccc}
\hline Red wine & $\mathbf{a}^{*}$ & $\mathbf{b}^{*}$ & $\mathbf{L}^{*}$ & $\mathbf{C}^{*}$ & $\mathbf{h}^{*}$ \\
\hline Joven (D.O. Ribera) & $39.74 \pm 2.37$ & $1.13 \pm 0.13$ & $61.48 \pm 2.50$ & $39.76 \pm 3.12$ & $1.63 \pm 0.16$ \\
Crianza (D.O. Ribera) & $31.18 \pm 1.86$ & $7.42 \pm 0.52$ & $67.16 \pm 2.21$ & $32.05 \pm 2.75$ & $13.39 \pm 1.22$ \\
Gran Reserva (D.O. Ribera) & $28.17 \pm 1.92$ & $9.00 \pm 0.45$ & $71.95 \pm 1.81$ & $29.57 \pm 2.44$ & $17.72 \pm 1.63$ \\
\hline Joven (D.O. Toro) & $51.07 \pm 3.20$ & $0.85 \pm 0.03$ & $54.63 \pm 2.34$ & $51.08 \pm 3.23$ & $0.95 \pm 0.06$ \\
Crianza (D.O. Toro) & $32.27 \pm 2.94$ & $6.47 \pm 1.12$ & $68.50 \pm 2.11$ & $32.91 \pm 1.77$ & $11.34 \pm 1.01$ \\
Reserva (D.O. Toro) & $25.91 \pm 2.02$ & $12.79 \pm 1.33$ & $71.89 \pm 1.89$ & $28.89 \pm 1.82$ & $26.27 \pm 1.31$ \\
\hline Reserva (D.O. Rioja) "Syrah” & $36.35 \pm 1.34$ & $8.16 \pm 0.84$ & $63.01 \pm 2.10$ & $37.25 \pm 1.64$ & $12.65 \pm 0.82$ \\
Reserva (D.O. Rioja) “Coupage” & $26.68 \pm 1.97$ & $10.96 \pm 1.35$ & $72.51 \pm 2.87$ & $28.84 \pm 1.82$ & $22.33 \pm 1.12$ \\
\hline $16 \quad$ Data: mean $\pm S D$ (n=3). & & & & \\
$17 \quad a^{*}$, redness; $b^{*}$, yellowness; $L^{*}$, lightness; C*, saturation; $h^{*}$, hue angle. & & & \\
18 & & & & &
\end{tabular}


Table 6. Results of Partial Least Squares regressions models (PLS-1).

\begin{tabular}{|c|c|c|c|c|c|c|}
\hline & \multicolumn{6}{|c|}{ Electronic Tongue data } \\
\hline & Parameter & $\mathbf{R}_{\mathrm{C}}^{2}(\mathbf{a})$ & $\mathbf{R M S E}_{\mathbf{C}}(\mathbf{b})$ & $\mathbf{R}_{\mathrm{P}}^{2}(\mathbf{c})$ & $\operatorname{RMSE}_{\mathbf{P}}(\mathrm{d})$ & Factors \\
\hline & TPI280 & 0.9343 & 2.0109 & 0.8956 & 2.6001 & 2 \\
\hline & Folin-C. & 0.9276 & 1.8972 & 0.8944 & 2.3496 & 3 \\
\hline \multirow{7}{*}{$\begin{array}{l}\text { Glories } \\
\text { color } \\
\text { parameters }\end{array}$} & $\mathbf{C D}$ & 0.9726 & 0.0371 & 0.9497 & 0.0525 & 3 \\
\hline & CI & 0.9712 & 0.0440 & 0.9475 & 0.0620 & 3 \\
\hline & $\mathbf{H}$ & 0.9873 & 0.0121 & 0.9689 & 0.0198 & 3 \\
\hline & dA $\%$ & 0.9885 & 0.5301 & 0.9720 & 0.8631 & 3 \\
\hline & $Y \%$ & 0.9869 & 0.3806 & 0.9707 & 0.5944 & 3 \\
\hline & $\mathbf{R} \%$ & 0.9822 & 0.4188 & 0.9623 & 0.6355 & 3 \\
\hline & B\% & 0.9701 & 0.1292 & 0.9558 & 0.1640 & 3 \\
\hline \multirow{9}{*}{$\begin{array}{l}\text { CIELab } \\
\text { color } \\
\text { parameters }\end{array}$} & $\mathbf{a}^{*}$ & 0.9893 & 0.8141 & 0.9800 & 1.1590 & 3 \\
\hline & $\mathbf{b}^{*}$ & 0.9845 & 0.4963 & 0.9625 & 0.8061 & 3 \\
\hline & $\mathbf{L}^{*}$ & 0.9754 & 0.9232 & 0.9496 & 1.3800 & 3 \\
\hline & $\mathbf{C}^{*}$ & 0.9927 & 0.6063 & 0.9813 & 1.0137 & 3 \\
\hline & $\mathbf{h}^{*}$ & 0.9905 & 0.8160 & 0.9793 & 1.2577 & 3 \\
\hline & \multicolumn{6}{|c|}{ ATR-FTIR data } \\
\hline & Parameter & $\mathbf{R}_{\mathrm{C}}^{2}(\mathbf{a})$ & $\mathrm{RMSE}_{\mathbf{C}}(\mathbf{b})$ & $\mathbf{R}_{\mathrm{P}}^{2}(\mathbf{c})$ & $\operatorname{RMSE}_{\mathbf{P}}(\mathrm{d})$ & Factors \\
\hline & TPI280 & 0.9195 & 2.2255 & 0.8908 & 2.7049 & 3 \\
\hline & Folin-C. & 0.9029 & 2.1966 & 0.8538 & 2.8123 & 4 \\
\hline \multirow{7}{*}{$\begin{array}{l}\text { Glories } \\
\text { color } \\
\text { parameters }\end{array}$} & CD & 0.9649 & 0.0420 & 0.9416 & 0.0566 & 4 \\
\hline & CI & 0.9635 & 0.0495 & 0.9392 & 0.0667 & 4 \\
\hline & $\mathbf{H}$ & 0.9305 & 0.0284 & 0.9125 & 0.0332 & 3 \\
\hline & dA $\%$ & 0.9490 & 1.1164 & 0.9339 & 1.3264 & 3 \\
\hline & $\mathbf{Y \%}$ & 0.9441 & 0.7871 & 0.9289 & 0.9265 & 3 \\
\hline & $\mathrm{R} \%$ & 0.9645 & 0.5912 & 0.9487 & 0.7419 & 4 \\
\hline & B\% & 0.9579 & 0.1533 & 0.9162 & 0.2258 & 5 \\
\hline \multirow{5}{*}{$\begin{array}{l}\text { CIELab } \\
\text { color } \\
\text { parameters }\end{array}$} & $\mathbf{a}^{*}$ & 0.9234 & 2.1737 & 0.9071 & 2.4988 & 3 \\
\hline & $\mathbf{b}^{*}$ & 0.9611 & 0.7864 & 0.9401 & 1.0183 & 4 \\
\hline & $\mathbf{L}^{*}$ & 0.9749 & 0.9323 & 0.9603 & 1.2252 & 4 \\
\hline & $\mathbf{C}^{*}$ & 0.9762 & 1.0964 & 0.9634 & 1.4179 & 4 \\
\hline & h* & 0.9713 & 1.4192 & 0.9553 & 1.8506 & 4 \\
\hline
\end{tabular}

21 (b), (d) Root mean square errors in calibration and prediction. 

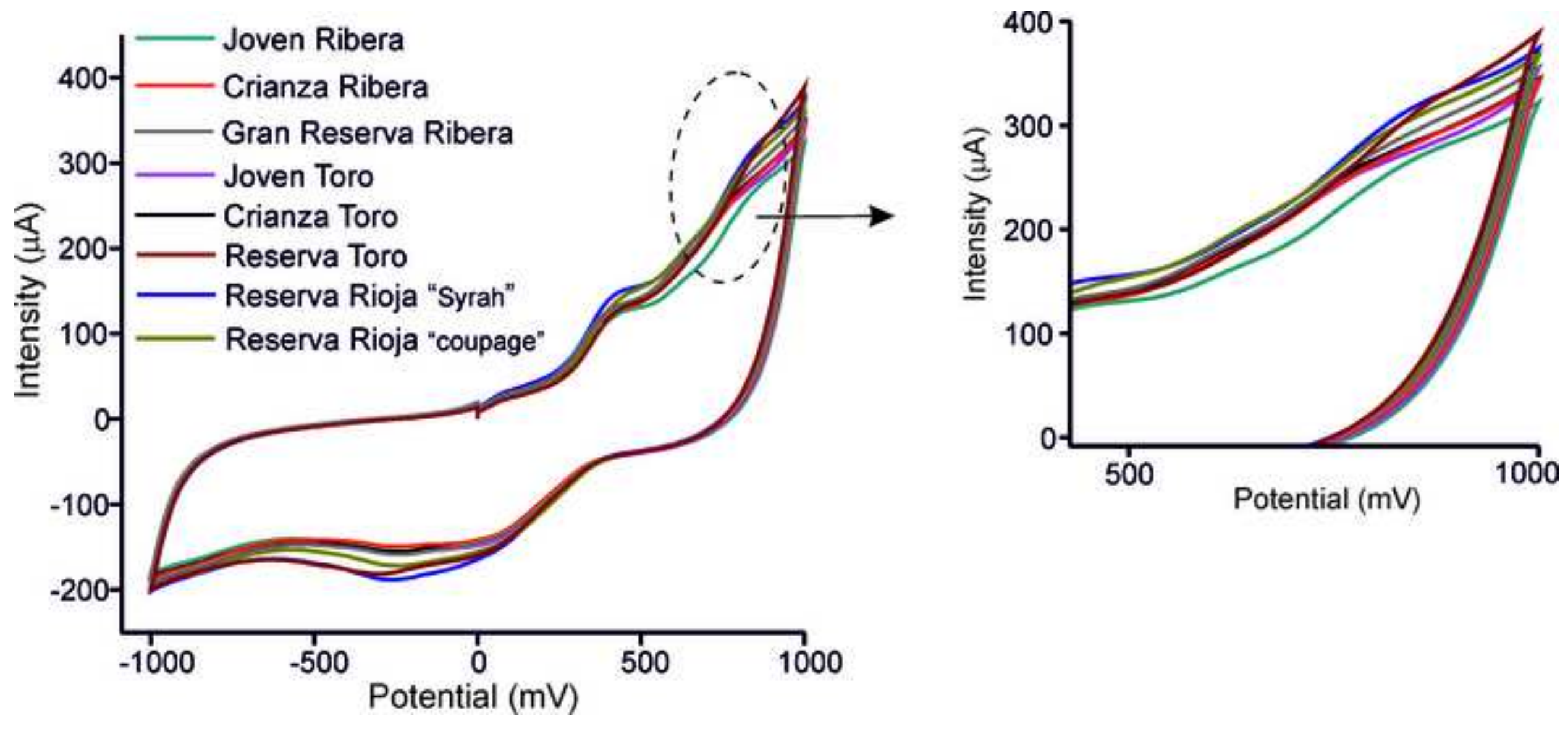


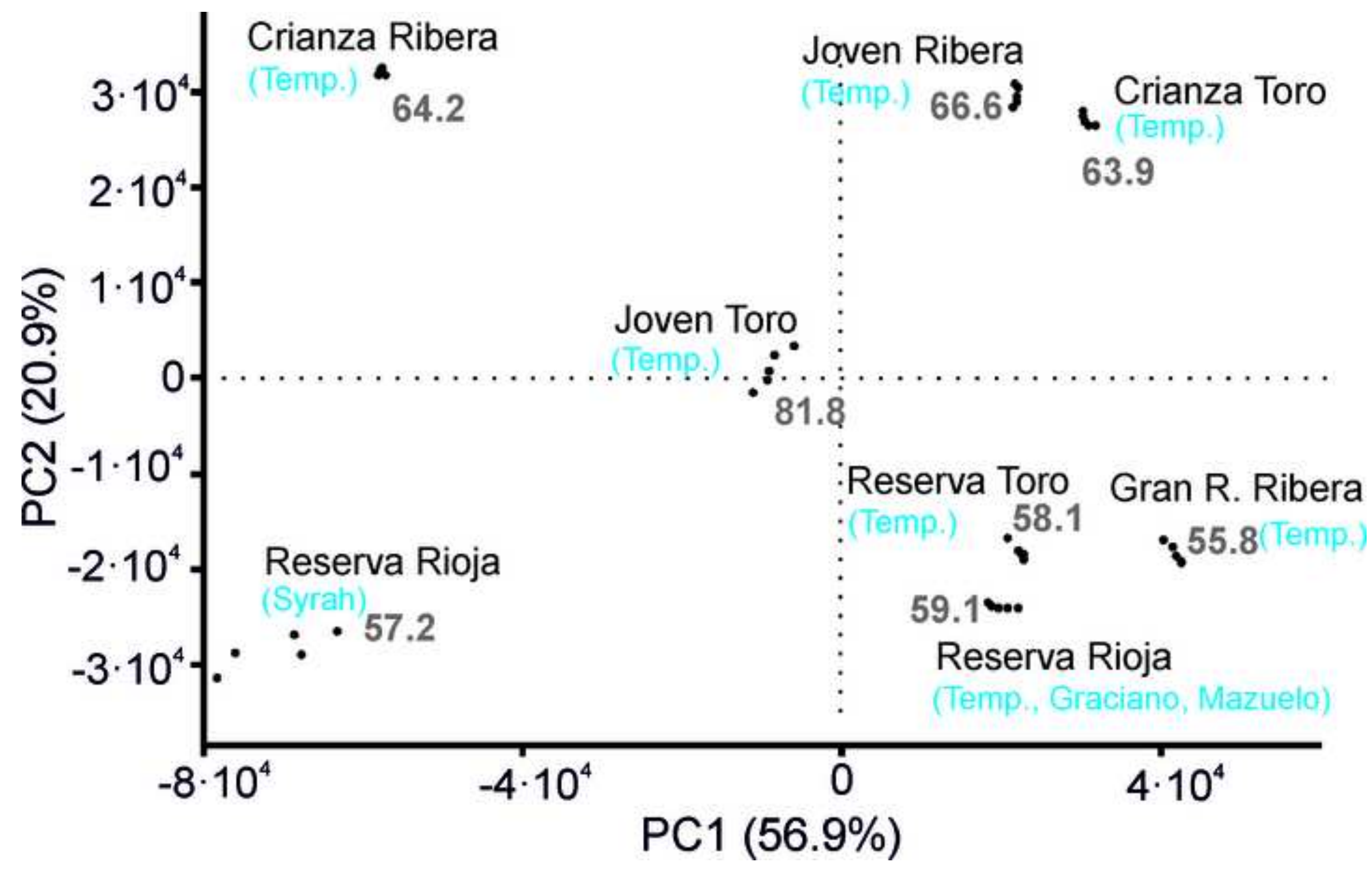




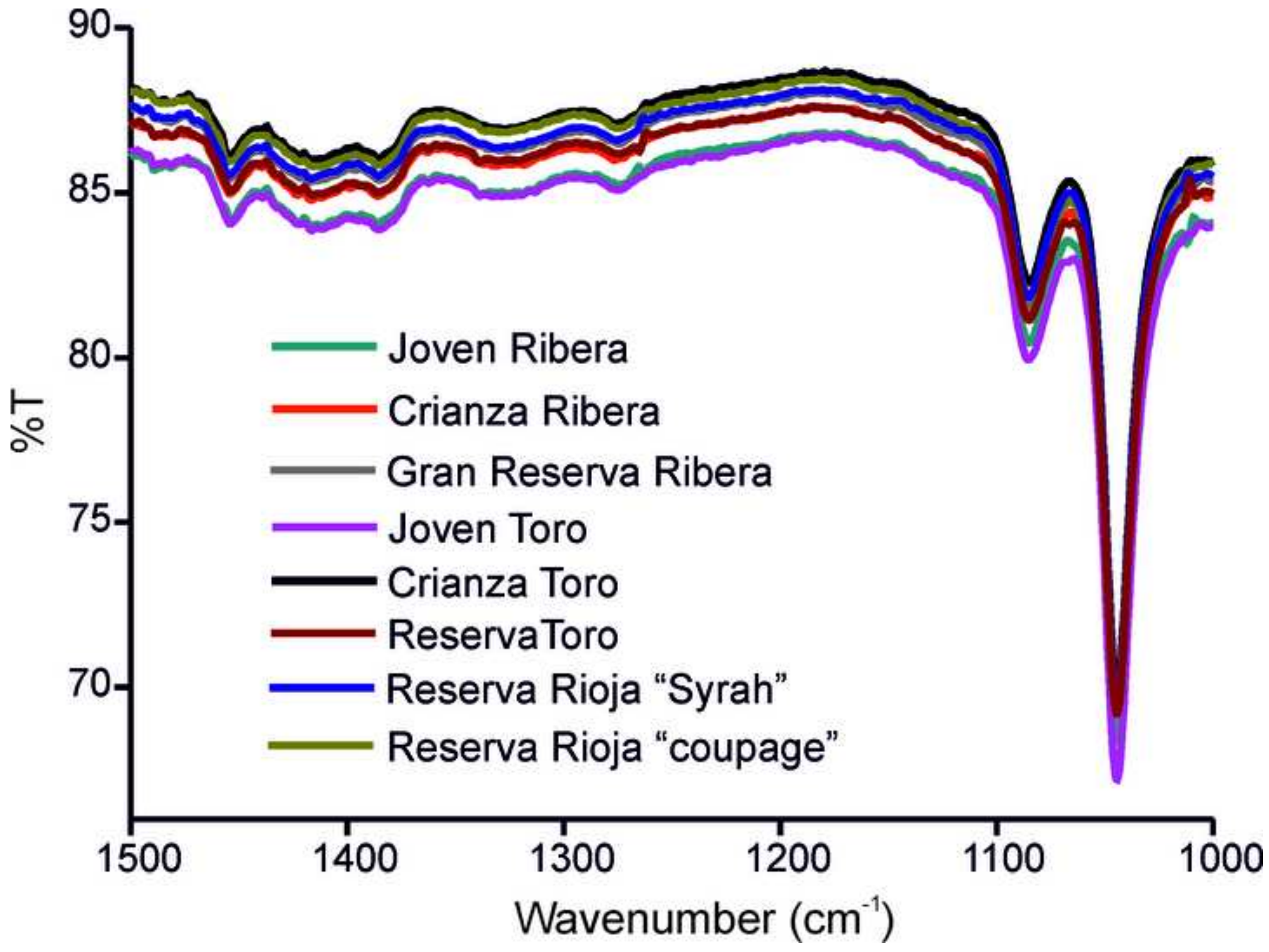




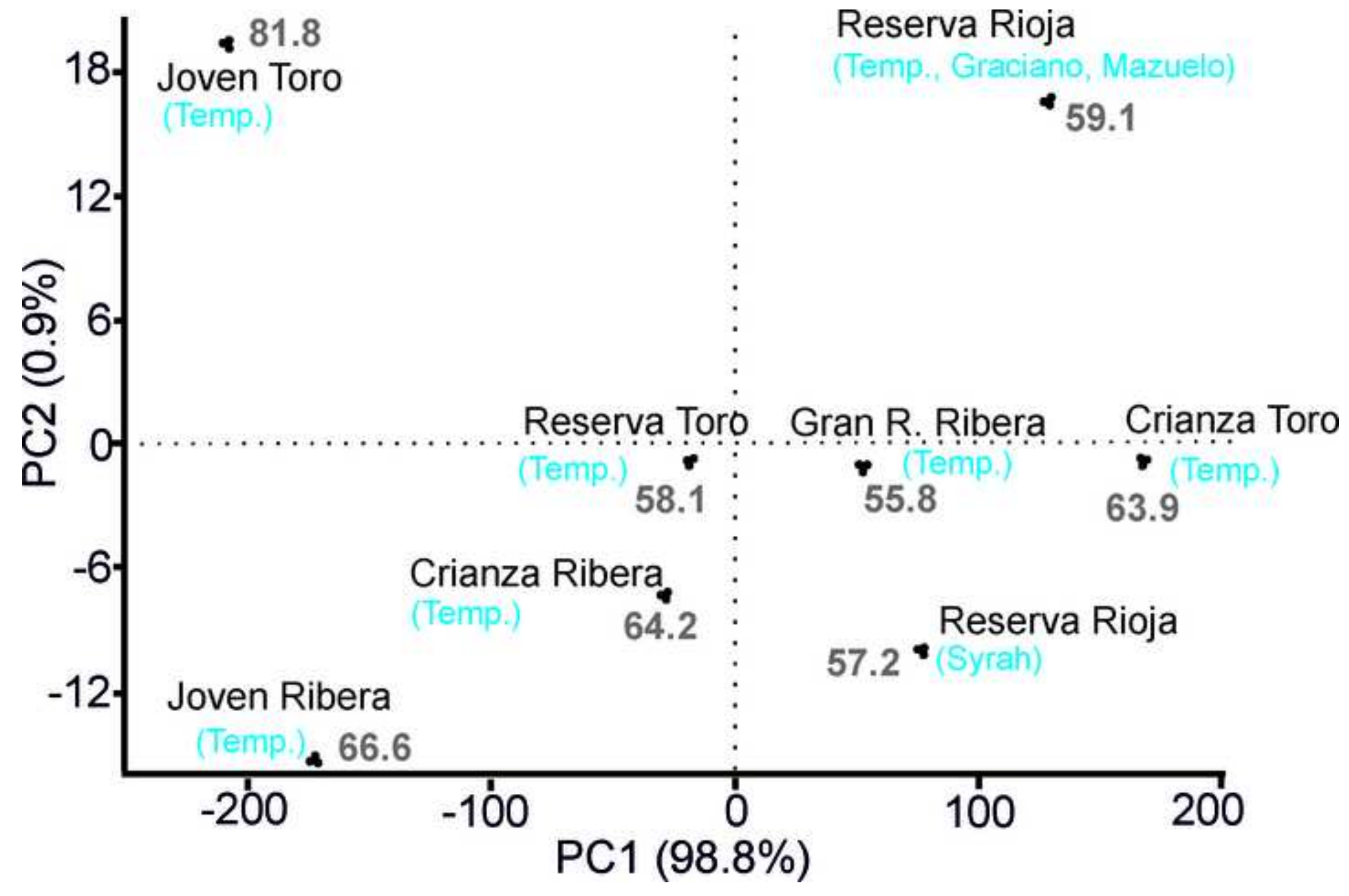




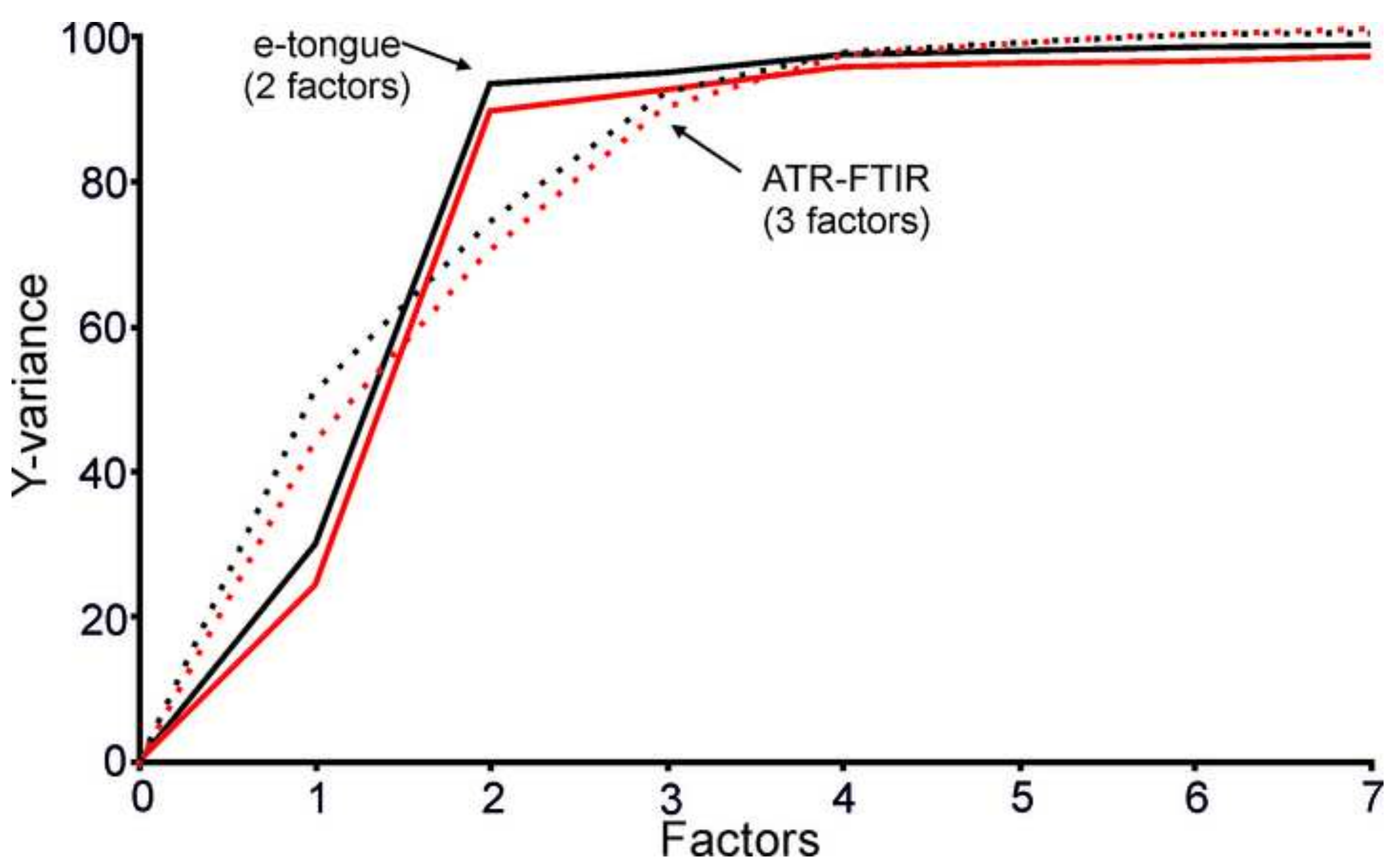


Figure captions
Click here to download Supplementary Material: Figure Captions_Garcia-Hernandez et al..docx 
Graphical abstract
Click here to download Supplementary Material: Graphical Abstract_Garcia-Hernandez et al..docx

Supplementary Material: Graphical Abstract Garcia-Hernandez et al.docx

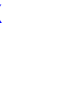


${ }^{*}$ Conflict of Interest Form

\section{Conflicts of Interest}

The authors declare that they have no conflict of interest. 